\title{
Balantidium coli in Pigs of Distinct Animal Husbandry Categories and Different Hygienic-Sanitary Standards in the Central Region of Rio Grande do Sul State, Brazil
}

\author{
Luís Antonio Sangioni', Sônia de Avila Botton', Fernanda Ramos', Gustavo Cauduro Cadore', \\ Silvia Gonzales Monteiro'ㄹ, Daniela Isabel Brayer Pereira ${ }^{3}$ \& Fernanda Silveira Flores Vogel ${ }^{1}$
}

\begin{abstract}
Background: Balantidium coli is a commensal protozoan that infects several animals, but it has pigs as its natural reservoir. In the presence of predisposing factors, $B$. coli can become pathogenic for swine, causing enteric lesions. Infections determined by this protozoan may be a risk to public health, due to dysentery in animal keepers and veterinarians. This study aimed to determine the occurrence of infection by B. coli in pigs of distinct husbandry categories, as well as unlike physiological state, kept in farms with different hygienic-sanitary standards, located in the central region of Rio Grande do Sul State in Brazil.

Materials, Methods \& Results: Stool samples were collected from 12 different farms with different hygienic-sanitary standards being four farms of finisher pigs $(\mathrm{G} 1 ; \mathrm{n}=287)$, four farms with pregnant females $(\mathrm{G} 2 ; \mathrm{n}=60)$ and four farms with lactation sows $(\mathrm{G} 3 ; \mathrm{n}=40)$, and all samples were submitted to coproparasitological analyses to verify the presence of cysts or trophozoites of B. coli. The infection levels were considered mild (1-100 cyst/trophozoite), moderate (101300 cyst/trophozoite) and high (>300 cysts/trophozoite). In addition, information about hygienic-sanitary conditions of each farm was collected. The occurrence of $B$. coli infection in all swine stool samples analyzed was 60.9\% (236/387); however, in G1, G2 and G3 was 54.7\% (157/287), 91.7\% (55/60) and 65\% (26/40) respectively. There was significant difference in the occurrence of G1 $(P<0.05)$ except between farms B and C $(67.9 \%$ and $56.6 \%$ respectively). There was also a significant difference $(P<0.05)$ between the occurrence of $B$. coli found in $\mathrm{G} 2$ and $\mathrm{G} 3$. The infection levels were considered predominantly mild in G1; and mild to moderate in G2 and G3.

Discussion: In this research it was confirmed the presence of B. coli in swine farms located in the central region of Rio Grande do Sul State in Brazil. This area is known as being an important producer of pigs in Brazil. The results obtained in this study, demonstrated that swine farms with better hygienic and sanitary standards, had mild infections by B. coli. However, the presence of intestinal parasites, especially protozoa, can occur even in properties with good management practices. However, protozoa infections can cause important production losses, especially when associated with other pathogens or nutritional problems. The occurrence of B. coli observed in pregnant (G2) and lactating (G3) females was significant, and the infection level was mild to moderate. These conditions suggest that pregnancy, childbirth and lactation are critical stages for females, mainly due to physiological stress, resulting in a change in the hormonal levels and immune status of the animals. Thus, these factors cause declines in the immune response of pigs making them susceptible to infections and the increase of cyst excretion of $B$. coli in feces. The abundance of protozoan cysts in feces contaminates the environment and increases the risk of infections in humans. In addition, it was demonstrated the occurrence of $B$. coli in an important site of swine production in RS, Brazil. B. coli is related to the physiological state of the animals and the hygienic and sanitary management in different categories of swine. In conclusion, this study highlights the epidemiological importance of swine as natural reservoir of Balantidium coli and the risk potential of infection to animals and humans. Additionally, sanitary program in farming pigs must be improved in order to guarantee healthy and food-safe product for consumers.
\end{abstract}

Keywords: protozoa, Balantidium coli, Sus domesticus, physiological status, hygienic-sanitary management. 


\section{INTRODUCTION}

Balantidium coli is a protozoan present in various regions of the world and with a wide variety of animal hosts, including human [19]. B. coli is a commensal agent of the intestinal tract of pigs [7], which are considered to be the natural reservoirs of this parasite [3]. In the presence of predisposing factors, this protozoan can become pathogenic, causing enteric lesions, favoring the invasion of intestinal mucosa and its multiplication [22]. B. coli can determine cases of dysentery, as well as it presents a risk to the public health. The presence of cysts of this parasite in the environment favors its direct and indirect propagation between humans and pigs. Thus, individuals working in the swine sector including: veterinarians, animal handlers and butchers constitute a risk group for $B$. coli infection $[11,17]$.

The life cycle of this parasite is direct, the trophozoites and cysts are released with the feces in the environment. Cysts are the infectious form and the individuals can become infected when ingesting them with the food or water. The highest occurrence rates of B. coli infection are in farms that have sanitary and husbandry problems [6]. The balantidiasis can determine economic losses in pig herds, since the main clinical signs are associated with inflammation of the intestinal mucosa, causing diarrhea and dehydration, mainly in herds with high density of animals $[10,15,16]$.

The aim of this study was to evaluate the occurrence of Balantidium coli in pig of different husbandry categories kept on farms with different hygienic-sanitary standards, located in an important pig production center in the central region of Rio Grande do Sul (RS) State, Brazil.

\section{MATERIALS AND METHODS}

\section{Origin and husbandry categories of swine}

In this investigation were included swine of Large White and Landrace breeds from pig farms of the central region of RS, Brazil. The animals were divided into the following groups: G1, finisher pigs ( $n=287$ ) of both gender, with six months of age and average weight of $110 \mathrm{~kg}$; G2, pregnant sows ( $\mathrm{n}=$ 60 ), with an average weight of $200 \mathrm{~kg}, 1$ to 5 reproductive cycles and G3, lactating sows $(n=40)$, with an average weight of $180 \mathrm{~kg}$, with an average 7 to 10 piglets/female. The animals in G1 were from four indoor intensive housing pig farms (A, B, C, D), in an integration and coordination system of complete cycles, specific for the finishing system, raising pigs in confinement and managed on an all-in all-out basis, keeping pigs of similar ages in groups in a common environment. The females from G2 and G3 were all from eight intensive housing pig farms: E, F, G, H (G2, pregnant sows) and I, J, K, L (G3, lactating sows). From all of the groups were collected information about the health, nutritional and reproductive status, as well as the type of husbandry management of the pig herds.

Coproparasitological analyses of swine fecal samples

Stool samples of all swine were collected individually, directly from the rectum into a plastic bag, identified, and placed in refrigerated cool boxes. The samples were transported and stored at $4^{\circ} \mathrm{C}$ at the Parasitic Diseases Laboratory, at Universidade Federal de Santa Maria (UFSM) until the exams.

The coproparasitological analyzes were performed by the methods of centrifugal flotation of zinc sulfate [4] and sucrose flotation [21]. Positive samples were considered when at least one cyst or trophozoite was visualized in the optical field. Thus, it was determined the levels of infection, being considered: mild infection (1-100 cysts/trophozoite), moderate (101-300 cysts/trophozoite) and high (<300 cysts/ trophozoite) [18].

\section{Statistical analysis}

The frequency of infection by B. coli in each animal husbandry category was obtained by dividing the total of the positive samples by the total samples collected, expressed as a percentage. All data were analyzed using the GraphPad Prisma program, using the chi-square test, with $95 \%$ confidence level to verify the difference of occurrence this protozoan among the groups [8].

\section{RESULTS}

The occurrence of Balantidium coli cysts in the feces studied was $60.9 \%$ (236/387). Among the groups (G1, G2 and G3), the occurrence of infection by protozoa was $54.7 \%(157 / 287), 91.7 \%(55 / 60)$ and $65 \%$ (26/40), respectively (Table 1 and 2).

There was difference between the occurrences of $B$. coli in animals from $\mathrm{G} 1$ herds $(P<0.05)$. However, the pig farms $\mathrm{B}$ and $\mathrm{C}$ did not differ $(67.9 \%$ and 
$56.6 \%$ respectively) (Table 1$)$. In addition, $B$. coli infection in G1 was considered mild in all animals from these four farms.

The occurrence of $B$. coli observed in pregnant females (G2) was $91.7 \%$ (55/60) and in lactating sows (G3) was $65.0 \%$ (26/40), no difference between G2 and G3 $(P<0.05)$ [Table 2]. In all farms G2 was verified the presence of the parasite; however, the intensity of infection ranged from mild $(25.5 \% ; 14 / 55)$, moderate $(54.5 \% ; 30 / 55)$ to high $(20 \% ; 11 / 55)$, being observed the higher occurrence of $B$. coli infection in moderate level $(54.5 \% ; 30 / 55)$. In the farms from G3 was found the presence of the parasite $(65 \% ; 26 / 40)$, moreover, the infection levels were similar, ranging from mild
$(50 \% ; 13 / 26)$ to moderate $(50 \% ; 13 / 26)$ in the females evaluated (Table 2).

The animals from G1 were kept in integration and intensive farming systems, which showed adequate health conditions. These farms had a program of biosecurity and animal welfare principles for all their herds. Conversely, the farms from G2 and G3 were all small and independent; however, some properties housed females in individual stalls and other in collective stalls. In both groups, G2 and G3, were denoted a lack of adequate sanitary and hygienic monitoring. Additionally, health problems were reported, especially involving abortions, high neonatal mortality and occurrence of infectious, parasitic and nutritional disorders.

Table 1. Distribution of the degree of infection and occurrence of Balantidium coli in finisher swine (G1) in pig farms of the central region of Rio Grande do Sul, Brazil.

\begin{tabular}{|c|c|c|c|c|c|c|}
\hline \multirow{2}{*}{ Group } & \multirow{2}{*}{ Farm } & \multirow{2}{*}{$\mathrm{n}^{*}$} & \multicolumn{3}{|c|}{ Degree of infection } & \multirow{2}{*}{$\begin{array}{l}\text { Total positive } \\
\text { samples }(\%)\end{array}$} \\
\hline & & & Mild & Moderate & High & \\
\hline \multirow{4}{*}{ G1 (Finishing) } & $\mathrm{A}^{a}$ & 111 & 28 & - & - & $28(25.2 \%)$ \\
\hline & $\mathrm{B}^{b}$ & 53 & 36 & - & - & $36(67.9 \%)$ \\
\hline & $\mathrm{C}^{b}$ & 60 & 34 & - & - & $34(56.6 \%)$ \\
\hline & $\mathrm{D}^{c}$ & 63 & 59 & - & - & $59(93.6 \%)$ \\
\hline Total & & 287 & 157 & - & - & $157(54.7 \%)$ \\
\hline
\end{tabular}

*Total number of faecal samples evaluated at each farm. Different lowercase letters $(a, b$ and $c)$ indicate significant difference between the properties $(P<0.05)$.

Table 2. Distribution of the infection degree and the occurrence of Balantidium coli in pregnant (G2) and lactating (G3) sows from pig farms in the central region of Rio Grande do Sul (RS), Brazil.

\begin{tabular}{|c|c|c|c|c|c|c|}
\hline \multirow{2}{*}{ Group } & \multirow{2}{*}{ Farm } & \multirow{2}{*}{$n^{*}$} & \multicolumn{3}{|c|}{ Infection degree ( $\%$ positive) } & \multirow{2}{*}{$\begin{array}{l}\text { Total positive } \\
\text { samples }(\%)\end{array}$} \\
\hline & & & Mild & Moderate & High & \\
\hline \multirow{4}{*}{$\begin{array}{c}\text { G2 } \\
\text { (Pregnant) }\end{array}$} & $\mathrm{E}^{a l}$ & 16 & $6(40 \%)$ & $7(46.7 \%)$ & $2(13.3 \%)$ & $15(93.8 \%)$ \\
\hline & $\mathrm{F}^{a l}$ & 3 & $3(100 \%)$ & - & - & $3(100 \%)$ \\
\hline & $\mathrm{G}^{a l}$ & 31 & $5(18.5 \%)$ & $15(55.6 \%)$ & $7(25.9 \%)$ & $27(87 \%)$ \\
\hline & $\mathrm{H}^{a l}$ & 10 & - & $8(80 \%)$ & $2(20 \%)$ & $10(100 \%)$ \\
\hline \multirow[t]{2}{*}{ Sub total } & & 60 & $14(25.5 \%)$ & $30(54.5 \%)$ & $11(20 \%)$ & $55(91.7 \%)^{A}$ \\
\hline & $\mathrm{I}^{a 2}$ & 22 & $8(72.7 \%)$ & $3(27.3 \%)$ & - & $11(50 \%)$ \\
\hline \multirow{3}{*}{$\begin{array}{c}\mathrm{G} 3 \\
\text { (Lactating) }\end{array}$} & $\mathrm{J}^{a 2}$ & 7 & - & 5 & - & $5(71.4 \%)$ \\
\hline & $\mathrm{K}^{a 2}$ & 7 & $1(25 \%)$ & $3(75 \%)$ & - & $4(57.1 \%)$ \\
\hline & $\mathrm{L}^{a 2}$ & 4 & $4(100 \%)$ & - & - & $4(100 \%)$ \\
\hline Sub total & & 40 & $13(50 \%)$ & $13(50 \%)$ & - & $26(65 \%)^{B}$ \\
\hline Total & & 100 & $27(27 \%)$ & $43(43 \%)$ & $11(11 \%)$ & $81(81 \%)$ \\
\hline
\end{tabular}

*Total number of faecal samples evaluated at each farm. Equal lowercase letters $(a)$ indicate that there was no significant difference $(P<0.05)$. Numbers 1 and 2 represent the comparisons between the farms within each group and indicate that there was no statistical difference $(P<0.05)$. The different capital letters (A and B) represent the comparison between $\mathrm{G} 2$ and $\mathrm{G} 3$ and indicate statistical difference $(2=14.51, \mathrm{CI}=95 \%, P<0.0001)$. 


\section{DISCUSSION}

The presence of $B$. coli cysts in the faeces of pigs has been demonstrated in previous studies $[9,13,15]$, which showed similar results to this research. The occurrence of this parasite can be justified because the swine is a natural reservoir of $B$. coli without presents any clinical signs [16]. Research involving other swine, as the wild boar (Sus scrofa scrofa), found different occurrences of this parasite in herds kept in captivity [13,14]. Mundim et al. [13] demonstrated the presence of B. coli in $38.5 \%$ of young boars, up to 12 months of age and $36.4 \%$ in adult animals, since the wild swine are also considered natural reservoirs of this protozoan.

Infections and gastrointestinal parasitic diseases are directly related to the sanitary conditions of the host and its habitat [12]. This could be verified by the results obtained in the properties where the finisher pigs were allocated (G1). In these farms, although there was the occurrence of cysts in $54.7 \%$ (157/287) of the samples, all infections were classified as mild degree (Table 1). This can be attributed to management procedures adopted in these properties and good hygiene conditions present in each housing system. It is noteworthy that these farms belong to integrated systems of industrial pig farming, which adopts strict sanitary hygienic standards in their herds. However, the presence of intestinal parasites, especially protozoa, may occur even in properties with good management practices [15].

The occurrence of $B$. coli observed between the two groups of pregnant females (G2) $(91.7 \%$; 55/60) and lactating (G3) $(65 \%$; 26/40) was significant with infections ranged from mild, moderate and high. However, the infection moderate was the most significant (Table 2). Nonetheless, only the G2 showed high infection level in the three farms. The occurrence of $B$. coli found in both groups of females may be related to the physiological status of the animals, since pregnancy, parturition and lactation stages are critical for females, mainly due to stress. Interestingly, in this study it can be observed that the pregnant sows had mild to high infection levels. This high incidence of $B$. coli can be explained by changes in hormone levels and the immune status of this category of animals, making them susceptible to infection and thereafter increasing of the excretion of cysts of B. coli in faeces [19]

The degree of infection by $B$. coli varies according to the livestock and sanitary management, as well as the category and physiological state of the animals. It is noteworthy that the clinical manifestations of balantidiasis in pigs occur more frequently in the following conditions: overcrowded farms, pregnant or lactating animals, nutritional disorders or when there is concurrent disease [15]. Generally, due to differences in livestock management, in animal extensive creations are observed major intestinal parasitism rates in relation to intensive farming. [10] In this work, we observed that the sanitary management in G2 and G3 as compared to G1, was less rigorous and the hygienicsanitary measures were precarious. In the properties of both groups (G2 and G3), denoted the absence of an antiparasitic control, presence of an incomplete vaccination schedule, a high density for housing and inadequate cleaning and disinfection of animal facilities. These factors are crucial for the increased occurrence of infection by $B$. coli, mainly in tropical and subtropical areas where pigs are raised in poor sanitary conditions [2]. Moreover, it was observed the production levels were low in G2 and G3, since there were reports of health problems involving abortions, high neonatal mortality and occurrence of infectious, parasitic and nutritional disorders in these swine herds.

Furthermore, B. coli is a source of infection for humans, especially the professionals who are in contact with the animals. The balantidiasis in human is characterized by gastroenteric disorders with presence feces containing blood. This infection must be differentiated from amebiasis, which is a major cause of diarrhea in humans $[5,16,22]$. The occurrence of $B$. coli is reported especially in populations of rural areas [10]. Risk factors that may favor balantidiasis transmission from animals to humans include the presence of pigs infected with B. coli, deficiency in basic sanitation, and shortcomings in education level of the population $[3,10,16,22]$. Thus, the results obtained in this study, support that the parasitological monitoring of pig herds, associated with the adoption of effective hygiene and sanitary measures, as well as the introduction of health education programs of population may help in the control and prevention of $B$. coli infection in animals and human.

\section{CONCLUSION}

This study demonstrates the presence of $\mathrm{Bal}$ antidium coli in commercial swine farms of different husbandry categories, with different physiological stages and hygienic-sanitary management located in 
the central region of RS. Furthermore, the occurrence of $B$. coli infection is higher in pregnant and lactating sows, especially kept in farms with deficiencies in hygiene and sanitary practices. Here, we highlight the epidemiological importance of swine as a natural reservoir of this protozoa and the potential risk in the transmission of Balantidium coli for animals and humans. Additionally, sanitary program in farming pigs must be improved in order to guarantee healthy and food-safe products for consumers.
Acknowledgements. The authors acknowledge all support from the Brazilian institutions for research, including: Programa de Pós-graduação em Medicina Veterinária (PPGMV)/UFSM, Conselho Nacional de Desenvolvimento Científico e Tecnológico (CNPq), Coordenação de Aperfeiçoamento de Pessoal de Nível Superior (Capes), and Fundação de Amparo à Pesquisa do Estado do Rio Grande do Sul (FAPERGS).

Declaration of interest. The authors report no conflicts of interest. The authors by themselves are responsible for the content and writing of the paper.

\section{REFERENCES}

1 Aguiar P.C. 2009. Aspectos epidemiológicos das parasitoses gastrintestinais de suínos naturalizados de criações familiares do Distrito Federal. 100f. Brasília, DF. Dissertação (Mestrado em Saúde Animal) da Universidade de Brasília.

2 Chalmers R.M. 2014. Chapter Fitfteen - Balantidium coli. In: Percival S., Yates M., Williams D., Chalmers R. \& Gray N. (Eds). Microbiology of Waterborne Diseases: Microbiological aspects and risks. 2nd edn. Amsterdan: Elsevier, pp.277-286.

3 Esteban J.G., Aguirre C., Angles R., Lawrence R., Ash L.R. \& Mas-coma S. 1998. Balantidiasis in Aymara children from the northern Bolivian Altiplano. American Journal of Tropical Medicine and Hygiene. 59(6): 922-927.

4 Faust E.C., D’Antoni J.S., Odom V., Miller M.J., Peres C., Sawitz W., Thomen L.F., Tobie J. \& Walker J.H. 1938. A critical study of clinical laboratory technics for the diagnosis of protozoan cysts and helminth eggs in feces. I. Preliminary communication. American Journal of Tropical Medicine. 18: 169-183.

5 Ferry T., Bouhour D., De Monbrison F., Laurent F., Dumouchel-champagne H., Picot S., Piens M.A. \& Granier P. 2004. Severe peritonitis due to Balantidium coli acquired in France. European Journal of Clinical Microbiology and Infectious Disease. 23: 393-395.

6 Fortes E. 2004. Parasitologia veterinária. 4.ed. São Paulo: Ícone, 608p.

7 Gezuele E.D., Fernández N., Dimenza M. \& Ponte P. 2005. Un caso de balantidiasis humana pauci sintomática. Revista Médica del Uruguay. 21(2): 164-166.

8 Hastings N.A.J. \& Peacock J.B. 1975. Statistical distributions: A handbook for students and practitioners. England: Longon Butterworths, 129p.

9 Ismail H.A., Jeon H.K., Yu Y.M., Do C. \& Lee Y.H. 2010. Intestinal parasite infections in pigs and beef cattle in rural areas of Chungcheongnam-do, Korea. Korean Journal of Parasitology. 48(4): 347-349.

10 Lai M., Zhou R.Q, Huang H.C. \& Hu S.J. 2011. Prevalence and risk factors associated with intestinal parasites in pigs in Chongqing, China. Research in Veterinary Science. 9: 121-124.

11 Marietto G.A., Martins T.F., Almeida S.M., Pereira R.E.P., Lima E.T. \& Andreatti Filho R.L. 2006. Cistos de Balantidium spp. em amostras fecais aviárias. Nosso Clínico. 9 (52): 62-63.

12 Monteiro S.G. 2011. Parasitologia na medicina veterinária. São Paulo: Editora Roca, 350p.

13 Mundim M.J.S., Mundim A.V., Santos A.L.Q., Cabral D.D., Faria E.S.M. \& Moraes F.M. 2004. Helmintos e protozoários em fezes de javalis (Sus scrofa scrofa) criados em cativeiro. Arquivo Brasileiro de Medicina Veterinária e Zootecnia. 56 (6): 792-795.

14 Nakauchi K. 1999. The Prevalence of Balantidium coli Infection in Fifty-Six Mammalian Species. Journal of Veterinary Medical Science. 61(1): 63-65.

15 Nishi S.M., Gennari S.M., Lisboa M.N.T.S., Silvestrim A., Caproni J.L. \& Umehara O. 2000. Parasitas intestinais em suínos confinados nos estados de São Paulo e Minas Gerais. Arquivos do Instituto Biológico. 67(2): 199-203.

16 Schuster F.L. \& Ramirez-Avila L. 2008. Current world status of Balantidium coli. Clinical Microbiology Reviews. 21(4): 626-638.

17 Shuster F.L. \& Visvesvara G.S. 2004. Amebae and ciliated protozoa as causal agents of waterborne zoonotic disease. Veterinary Parasitology. 126: 91-120. 
18 Silva A.S., Zanette R.A. \& Monteiro S.G. 2007. Parasitismo por Balantidium coli em nutria (Myocastor coypus) no município de Santa Maria, RS - Brasil. Estudos de Biologia Ambiente e Diversidade. 29(68): 341-343.

19 Sobestiansky J. \& Barcellos D. 2007. Doenças dos suínos. Goiânia: Cânone Editorial. 770p.

20 Stensvold C.R., Lebbad M. \& Verweij J.J. 2011. The impact of genetic diversity in protozoa on molecular diagnostics. Trends in Parasitology. 27(2): 53-58.

21 Willis H.H. 1921. A simple levitation method for the detection of wookworm ova. Medicine Journal of Australia. 8: 375-376.

22 Yazar S., Altuntas F., Sahin I. \& Atambay M. 2004. Dysentery caused by Balantidium coli in a patient with nonHodgkin's lymphoma from Turkey. World Journal of Gastroenterology. 10(3): 458-459. 